ANNALS JOURNAL CLUB

\title{
The Next Step in Expanding Treatment of Opioid Use Disorder?
}

\author{
Michael E. Jobansen, MD, MS, Associate Editor, Rosalie Dillion, DO, Grant Family Medicine \\ Ann Fam Med 2022;20:100. https://doi.org/10.1370/afm.2783.
}

$\mathrm{T}$ The Annals of Family Medicine encourages readers to develop a learning community to improve health care and health through enhanced primary care. With the Annals Journal Club, we encourage diverse participants to think critically about important issues affecting primary care and act on those discussions.'

\section{HOW IT WORKS}

The Annals provides discussion tips and questions related to one original research article in each issue. We welcome you to post a summary of your conversation to our eLetters section, a forum for readers to share their responses to Annals articles. Further information and links to previous Annals Journal Club features can be found on our website.

\section{CURRENT SELECTION}

Zittleman L, Curcija K, Nease DE, et al. Increasing capacity for treatment of opioid use disorder in rural primary care practices. Ann Fam Med. 2022:20(1):18-23.

\section{Discussion Tips}

Opioid use disorder is an under-treated condition. Primary care offers a platform to expand treatment far beyond current utilization, but previous efforts to expand prescribing through increasing buprenorphine waivers has not optimized the system for a variety of other reasons. ${ }^{2,3}$ Given this context, the authors of this study attempted to implement and evaluate a more complex intervention in hopes of increasing the utilization of buprenorphine.

\section{Discussion Questions}

- What question is asked by this study and why does it matter?

- How does this study advance beyond previous research and clinical practice on this topic?

- How strong is the study design for answering the question?

- What is a multi-level model? Are these statistical models common in primary care research? Why is it important that the authors used this type of model in this study?

- To what degree can the findings be accounted for by:

- How clinics were selected, excluded, or lost to

follow-up?

- How the main variables were measured?

- What the intervention group was compared to?

- Confounding (false attribution of causality because 2 variables discovered to be associated actually are associated with a 3rd factor)?

- Chance?

$\circ$ How missing data were dealt with in the study? Why is missing data important to consider?

- How the findings were interpreted?

- What are the main study findings?

- How comparable is the study sample to similar patients in your practice or region? What is your judgment about the transportability of the findings?

- What contextual factors are important for interpreting the findings?

- How might this study change your practice? Policy? Education? Research?

- Who are the constituencies for the findings, and how might they be engaged in interpreting or using the findings?

- What are the next steps in interpreting or applying the findings?

- What researchable questions remain?

\section{References}

1. Stange KC, Miller WL, McLellan LA, et al. Annals Journal Club: it's time to get RADICAL. Ann Fam Med. 2006;4(3):196-197. https://AnnFamMed.org/ cgi/content/full/4/3/196

2. Stein BD, Sorbero M, Dick AW, Pacula RL, Burns RM, Gordon AJ. Physician capacity to treat opioid use disorder with buprenorphine-assisted treatment. JAMA. 2016;316(11):1211-1212. 10.1001/jama.2016.10542

3. Andrilla CHA, Coulthard C, Larson EH. Barriers rural physicians face prescribing buprenorphine for opioid use disorder. Ann Fam Med. 2017;15(4):359362. 10.1370/afm.2099 